\title{
Influence of solubor, biozyme and triacontanol on leaf and fruit nutrient content of apple cv. RED DELICIOUS
}

\author{
Mohd. Zubair*, S.S. Hussain, Munib-U-Rehman and Jahangir Ah. Baba \\ Krishi Vigyan Kendra (E.T.C., SKUAST-K.), Malangpora, PULWAMA(J\&K) INDIA \\ (Email : takzubair@gmail.com)
}

\begin{abstract}
The decreasing trend in apple productivity during the last decade due to changing climate scenario has caused a serious concern to the fruit growers and planners of the country. Several factors like inadequate pollinizer proportion, reduction in natural population of pollinating agents, occurrence of spring frosts, hails and gales, nutrient deficiencies, droughts etc. are the factors leading to poor fruit setting in Delicious apple (Gautam et al., 2004). The present studies on influence of solubor, biozyme and triacontanol on leaf and fruit nutrient content of apple cv. RED DELICIOUS"were carried out in the Division of Fruit Science, SKUAST-Kashmir, Shalimar, Srinagar during the year 2013 and 2014. Twenty five year old apple trees of cv. RED DELICIOUS were selected at the Sher-e-Kashmir University of Agricultural Sciences and Technology, Shalimar, Kashmir. In experiment: chemicals of solubor $(0.1 \%)$ biozyme ( $1.5 \mathrm{ml} / \mathrm{lit})$ and triacontanol $(10 \mathrm{ppm})$ and their combinations were sprayed at three timings: (i) at pink bud stage (ii) three weeks after fruit set of apple (iii) two months after second spray. Two months after second spray, solubor was replaced with $0.5 \% \mathrm{CaCl}_{2}$ while going through the results, leaf nitrogen content not significantly influenced by different treatments. However, maximum leaf phosphorus $(0.26 \%)$, potassium $(2.62 \%)$, calcium $(2.46 \%)$ and magnesium $(0.88 \%)$ was recorded in solubor + biozyme + triacontanol followed by solubor + biozyme. The leaf boron increased significantly with solubor + biozyme + triacontanol and solubor + biozyme ( 48.00 and $47.25 \mathrm{ppm})$ followed by solubor + triacontanol. However, data with respect to leaf nitrogen/ calcium ratio were found to be statistically non-significant. Maximum fruit nitrogen $(0.39 \%)$, phosphorus $(0.11 \%)$, potassium $(0.99 \%)$, calcium $(0.049 \%)$, magnesium $(0.078 \%)$ and boron $(19.82 \mathrm{ppm})$ was obtained from solubor + biozyme + triacontanol followed by solubor + biozyme. However, $\mathrm{N} / \mathrm{Ca}$ (17.96) ratio was calculated from control followed by triacontanol (12.33) and biozyme (10.62) and lowest was observed in solubor + biozyme + triacontanol (8.06). While going through the results of both the experiments, it is revealed that the combinations of solubor, biozyme and triacontnaol were best to improve the fruit set and yield of apple fruits. It is clear from results that bio-stimulants increase nutrients through foliar application and thus will improve the fruit yield and quality of apple. In addition bio-stimulants are safe for human and animal and environment to get lower pollution and reduce soil salinity.
\end{abstract}

Key Words : Apple, Chemicals, urea, Leaf, Fruit nutrient contents

View Point Article : Mohd. Zubair, Hussain, S. S., Munib-u-Rehman, Baba, Jahangir Ah. (2018). Influence of solubor, biozyme and triacontanol on leaf and fruit nutrient content of apple cv. RED DELICIOUS. Internat. J. agric. Sci., 14 (1) : 85-91, DOI: 10.15740/HAS/ IJAS/14.1/85-91.

Article History : Received : 03.05.2017; Revised : 11.11.2017; Accepted : 24.11.2017

\footnotetext{
* Author for correspondence:
} 